\title{
Rsp activates expression of the Cnt system in Staphylococcus aureus
}

\author{
Laura Vinué and David C. Hooper
}

\begin{abstract}
Background: The Cnt system is crucial for the optimal import of essential metals in metal-limiting conditions and contributes to virulence in S. aureus. In a screen for regulators of efflux pumps in a phage-based ultra-high-density transposon library, we identified Rsp as a candidate regulator of the cntE gene.

Results: A two-fold decrease in expression of all genes of the cnt operon was observed by RT-qPCR in the rsp mutant compared to the parental strain, indicating that Rsp acts as an activator of the cnt operon. To determine whether the Rsp activation depends on iron, we compared mutant and parent cnt expression under varying metal conditions. A 2-fold reduction in cnt gene expression was detected in the rsp mutant in TSB, and a slightly smaller decrease (1.9, 1.7, and 1.5-fold changes for $c n t K, c m t A$, and $c n t E$ respectively) was observed after addition of dipyridyl. The greatest decrease was seen with addition of $\mathrm{FeSO}_{4}$ (4.1, 5.3 and 6.3-fold changes for $\mathrm{cntK}, \mathrm{cm}$ tA and $\mathrm{cntE}$ respectively). These findings suggest that Rsp activates the cnt operon in low and high iron conditions. To study the relationship between Rsp and the cnt repressors Fur and Zur, we created single and double mutants. Both fur and zur single mutants had significant increases in cnt gene expression compared to the parental strain, as did the fur rsp double mutant. The zur rsp double mutant also had a significant increase in $c n t K$ expression and a trend in increases in $c n t A$ and $c n t E$ expression just below statistical significance. Thus, the ability of Fur and Zur to repress cnt gene expression are not eliminated by the presence of Rsp. However, there were significantly smaller increases in cnt gene expression in the double mutants compared to single mutants, suggesting that Rsp activation can still occur in the absence of these repressors. To determine if Rsp directly modulates expression of cnt genes, incubation of purified Rsp caused a DNA-specific band shift for the cntK and cntA promoters.
\end{abstract}

Conclusions: Rsp activation may act to maintain basal cellular levels of staphylopine to scavenge free metals when needed, in addition to metal dependent regulation by Fur and Zur.

\section{Background}

Staphylococcus aureus poses a serious risk to public health due to its prevalence as a colonizer of skin and nares, its ability to cause a wide range of infections, and the increasing incidence of antibiotic-resistant strains [1]. During infection, $S$. aureus is confronted with a robust host innate immune response and an environment with low availability of free iron, manganese, and zinc $[1,2]$. To overcome this host defense mechanism, S. aureus has evolved a diverse array of metal acquisition strategies that facilitates its

\footnotetext{
* Correspondence: Ivinue-santolalla@mgh.harvard.edu

Division of Infectious Diseases, Massachusetts General Hospital, Harvard

Medical School, 55 Fruit St, Boston, MA 02114-2696, USA
}

proliferation and pathogenesis in host tissues [2, 3]. S. aureus captures free metals from the host through high-affinity transporter systems or small chelating molecules called metallophores [3].

Staphylopine (StP) is a nicotianamine-like metallophore secreted by $S$. aureus, with a remarkably broad spectrum of metal ligands, including nickel, cobalt, copper, zinc, and iron $[4,5]$. The nine-gene cntKLMABCDFE operon is required for StP synthesis and trafficking. The first three genes $c n t K-M$ are responsible for StP biosynthesis; $c n t A-F$ encode the importer of the StP-metal complex; and CntE is involved in the export of StP [4-7].

(c) The Author(s). 2020 Open Access This article is licensed under a Creative Commons Attribution 4.0 International License, which permits use, sharing, adaptation, distribution and reproduction in any medium or format, as long as you give appropriate credit to the original author(s) and the source, provide a link to the Creative Commons licence, and indicate if changes were made. The images or other third party material in this article are included in the article's Creative Commons licence, unless indicated otherwise in a credit line to the material. If material is not included in the article's Creative Commons licence and your intended use is not permitted by statutory regulation or exceeds the permitted use, you will need to obtain permission directly from the copyright holder. To view a copy of this licence, visit http://creativecommons.org/licenses/by/4.0/ The Creative Commons Public Domain Dedication waiver (http://creativecommons.org/publicdomain/zero/1.0/) applies to the data made available in this article, unless otherwise stated in a credit line to the data. 
The Cnt system is repressed by Fur and Zur in the presence of iron and zinc, respectively, with tight control of the StP biosynthesis genes and a looser control of the genes responsible for its export and recovery [8]. Besides the iron-dependent regulator Fur, an iron-independent regulation of the cnt regulon has been considered but not yet identified [8].

In this study, we identified a novel regulator of the cnt operon that activates the system in addition to the metal-dependent Fur and Zur repressors.

\section{Results}

Regulation of the cnt operon by the AraC-type regulator, Rsp

Fur is an iron-dependent transcriptional regulator that uses Fe (II) as a cofactor and negatively regulates transcription of iron transport genes by binding to the two Fur boxes present in the cnt operon [8]. Besides the Furdependent regulation, a Fur-independent regulation by iron was also described, but these regulators have not been identified [8], and nothing is known about an ironindependent regulation of the cnt operon. In addition, no activators of the cnt system has been described.

In a screen for regulators of efflux pumps and/or exporters, using ciprofloxacin selection in a previously reported phage-based ultra-high-density transposon library procedure [9] we identified Rsp, as a candidate regulator of the $c n t E$ exporter gene. The screen used a selection at varying concentrations of ciprofloxacin, a substrate of both the NorA and NorB efflux pumps, and identified differences in knockouts of genes of transcriptional regulators.

To evaluate further the role of Rsp in cnt expression, a $r s p$ mutant (NE1304) and its parental strain (USA300 JE2) from the Nebraska Transposon Mutant Library [10] were used to measure the expression of all genes of the cnt operon by RT-qPCR. As shown in Table 1, the expression of all genes in cht operon decreased by an average of two-fold in the rsp mutant compared to the parental strain, being statistically significant for all genes of the operon, indicating that Rsp acts as an activator not only of $c n t E$ but also of the entire $c n t$ operon. This finding was further supported by the results that restoration of the presence of Rsp via introducing plasmid encoding $r s p$ gene (pRsp) reestablished the expression of cntK, cntA and cntE genes to the levels of wild type strain (USA300 JE2) with the empty plasmid as the control (Fig. 1).

\section{Rsp activation acts in iron-independent manner}

To determine if the Rsp activation acts in ironindependent manner, we measured the level of expression of $c n t K, c n t A$ and $c n t E$ under varying metal conditions. As it is shown in Fig. 2a, the transcript levels of the three genes in the $r s p$ mutant strain decreased in the
Table 1 Relative expression of the cnt operon in a $\Delta r s p$ mutant strain

\begin{tabular}{lll}
\hline \multirow{2}{*}{ Genes } & \multicolumn{2}{l}{ Fold change relative to USA300 JE2 (WT strain) } \\
\cline { 2 - 3 } & Mean & SEM \\
\hline \multicolumn{2}{l}{ StP biosynthesis } \\
cntK & 0.477 & 0.190 \\
cntL & 0.166 & 0.081 \\
cntM & 0.711 & 0.167 \\
StP importer & & \\
cntA & 0.712 & 0.175 \\
cntB & 0.439 & 0.117 \\
cntC & 0.571 & 0.129 \\
cntD & 0.504 & 0.145 \\
cntF & 0.439 & 0.051 \\
StP exporter & & \\
cntE & 0.377 & 0.052 \\
\hline
\end{tabular}

SEM Error standard of the mean

three conditions tested, rich media (TSB), metaldepleted (TSB + DIP) and metal-replete medium (TSB + $\mathrm{DIP}+\mathrm{Fe}$ ) relative to the wild type strain (USA300 JE2). A 2-fold change was detected in TSB for all the genes of the operon. A slightly smaller decrease (1.9-, 1.7- and 1.5-fold changes for $c n t K, c m t A$ and $c n t E$, respectively) was observed under DIP conditions. Additionally, the decrease was amplified with addition of $50 \mu \mathrm{M} \mathrm{FeSO}_{4}$ to DIP media (4.1-, 5.3- and 6.3-fold changes for $c n t K, c n t A$ and $c n t E$ respectively) (Fig. $2 \mathrm{a}$ ), likely due to the maximum level of repression of Fur in an iron-rich media. These data suggest that Rsp can activate the cht operon under varying levels of iron-dependent repression by Fur, thereby supporting a basal level of the cnt gene expression in the cells. In complementation assays in the iron-depleted media, the decrease in cnt gene expression observed in the $r s p$ mutant strain carrying the empty plasmid pTZN10 (3.3-, 2- and 3.2-fold changes detected for $c n t K, c m t A$ and $c n t E$, respectively) was complemented to wild type levels with the plasmid containing $r s p$ (pRsp). (1.4-, 0.92- and 1.2-fold changes for cntK, cntA and $c n t E$, respectively) (Fig. 2B1). The same complementation was observed in the iron-repleted media, when pRsp was introduced into the rsp mutant. Compared to the $r s p$ mutant strain with the empty plasmid pTZN10, the $r s p$ strain with pRsp exhibited changes of 3.47 - vs 1.35-fold for $c n t K, 3.3$-vs 0.96 -fold for $c n t A$ and 2.7 -vs 0.9 -fold for $c n t E$, further confirming the effect of the Rsp activation in varying iron conditions (Fig. 2B2).

Relationship between the repressors Fur and Zur and the activator Rsp in the regulation of the cnt operon

As noted, Fur negatively regulates transcription of the cht operon in an iron-dependent manner [8]. In 


\section{$\square \mathrm{USA} 300 \mathrm{JE} 2 \mathrm{pTZN10}$ - rsp mutant pTZN10 $\square r s p$ mutant pRsp}

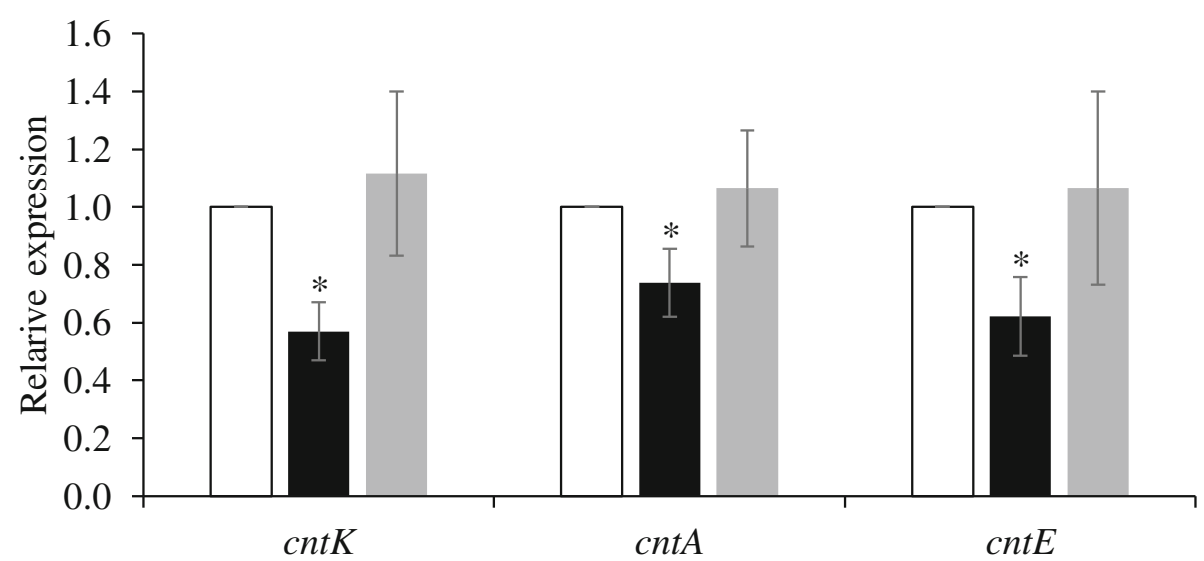

Fig. 1 Complementation of Rsp in rich media. Relative expression of $c n t K, c n t A$ and $c n t E$ genes in the rsp mutant strain with an empty plasmid pTZN10 and a plasmid expression rsp (pRsp) relative to USA300 JE2 with the empty plasmid were assessed by RT-qPCR. The bars represent the means of relative expression from at least three independent experiments. The error bars show standard errors of the means. Statistical differences were determined by Mann-Whitney U Test. rsp mutant pTZN10 showed lower expression for the three genes (cntK, cntA, cntE) than the USA300 JE2 pTZN10 strain $\left.{ }^{*} P<0.05\right)$, having no differences between USA300 JE2 pTZN10 and the complementation strain rsp mutant pRsp

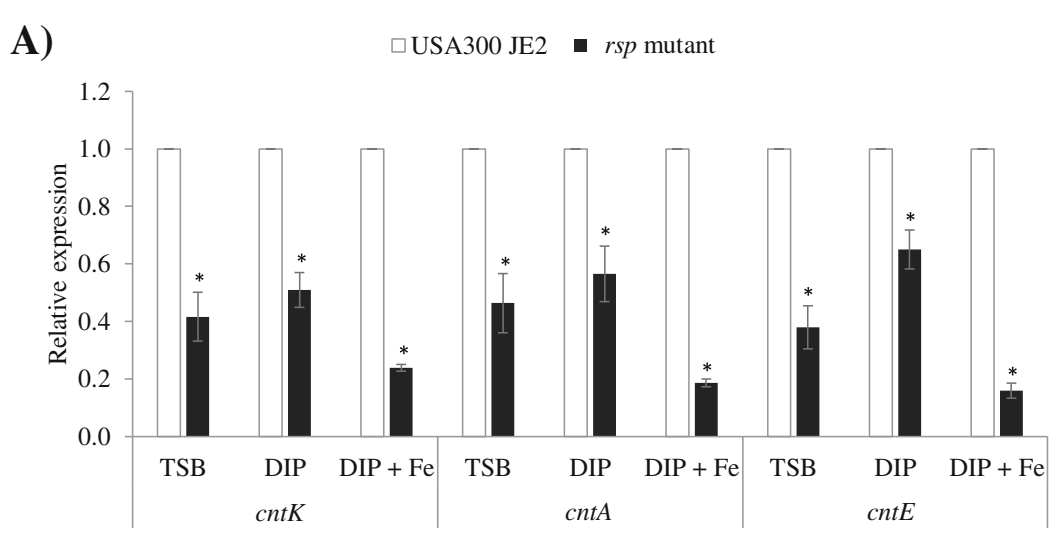

B)

B1)

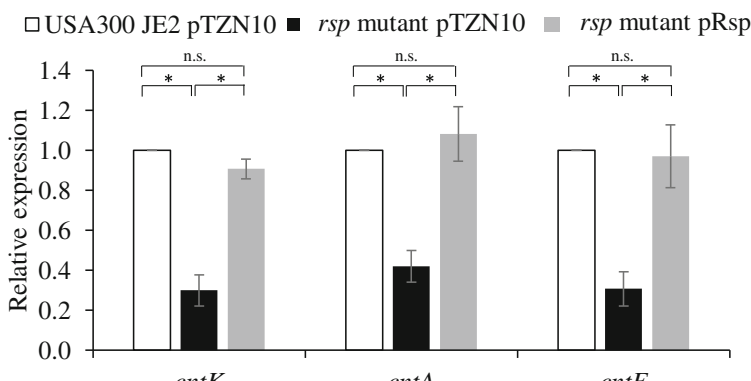

B2)

\section{Iron-repleted media}

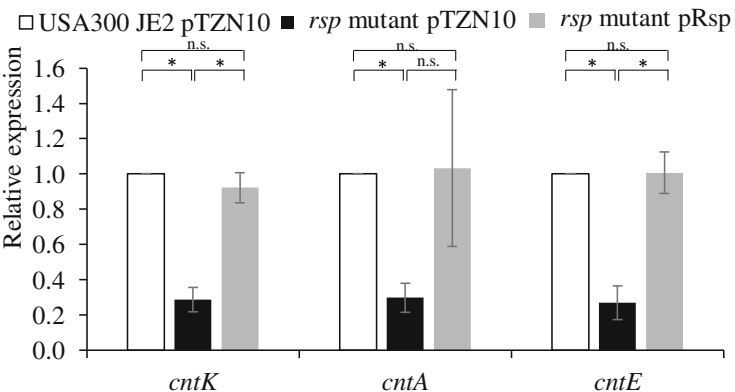

Fig. 2 Rsp activation acts in iron-independent manner. a Relative expression of $c n t K$, $c n t A$ and $c n t E$ genes in the rsp mutant strain relative to USA300 JE2 strain under different metal conditions: rich media (TSB), iron-depleted media (DIP = TSB + dipyridyl $400 \mu \mathrm{M}$ ) and iron-repleted media $(\mathrm{DIP}+50 \mu \mathrm{M}$ FeSO 4 ) were assessed by RT-qPCR. $\mathbf{b}$ Complementation of Rsp. Relative expression of cntK, cntA and cntE genes in the rsp mutant strain with an empty plasmid pTZN10 and a plasmid expressing rsp (pRsp) relative to USA300 JE2 with the empty plasmid were assessed by RT-qPCR in (B1) Iron-depleted media (DIP $=$ TSB + dipyridyl $400 \mu \mathrm{M}$ ). (B2) Iron-repleted media (DIP + $50 \mu \mathrm{M} \mathrm{FeSO} 4$ ). The bars represent the means of relative expression from at least three independent experiments. The error bars show standard errors of the means. Statistical differences were determined by Mann-Whitney $\cup$ Test. $\left({ }^{*} P<0.05\right.$; n.s. = not significant) 
addition, zinc regulation of the cnt operon through the repressor Zur has been previously reported [8]. To determine the possible interaction of Rsp with Fur and Zur in controlling cht expression, we created single (fur, zur) and double mutants (fur rsp, zur rsp) in a USA300 background and measured the expression of cht genes. As expected, the expression of $c n t K$, cntA and $c n t E$ genes was increased substantially in the fur mutant $(23-, 14-$, and 7-fold, respectively) as well as the zur mutant (15-, 17-, and 13-fold, respectively) (Fig. 3a). Although these increases were reduced in the $r s p$ double mutants (by1.5- to 1.6-fold for fur rsp and by 1.3- to 1.6-fold for zur rsp) relative to single mutants there remained substantial increases in cht gene expression relative to the parental strain the double mutants (7- to 15-fold for fur rsp and 7- to 12-fold for zur rsp). Thus, repression by Fur and Zur can occur in the presence and absence of Rsp activation, however, was sufficient to significantly partially counter Fur repression for $c n t K$ and $c n t E$ and to partially counter Zur repression for cntA and cntE (Fig. 3b).

\section{Binding of Rsp to the promoter region of the cnt operon}

To determine if Rsp acts directly to modulate expression of cht genes, Rsp was expressed in a pQE-9 (His tag expression vector) previously constructed [11] using E. coli SG13009 containing the pREP4 plasmid as a host. After induction by IPTG and further purification on a nickel

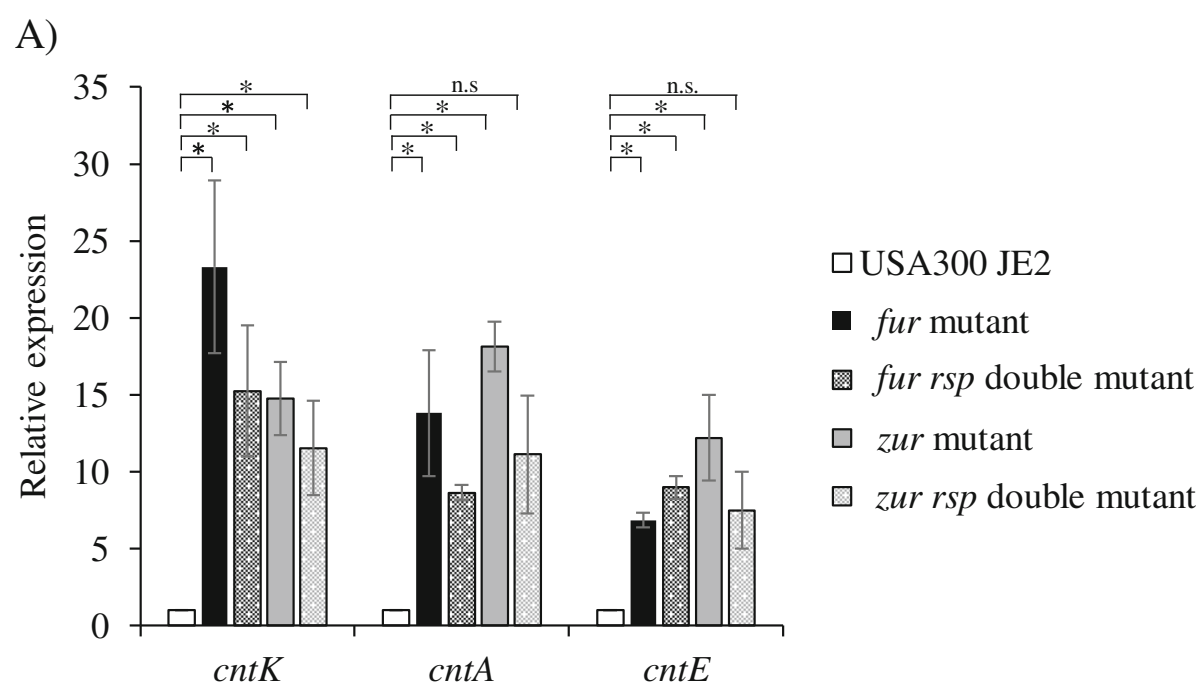

B)

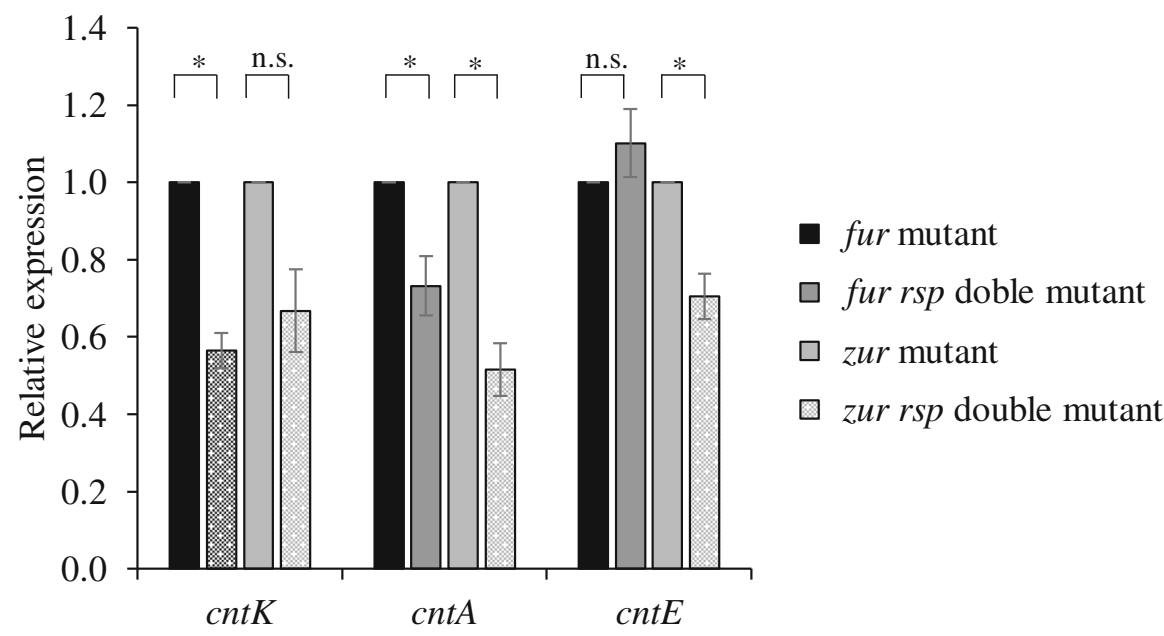

Fig. 3 Rsp activation of the cnt operon can act independently of the repressors Fur and Zur. Relative expression of cntK, cntA and cntE genes in the fur, zur single mutants and fur rsp, zur rsp double mutants relative to USA300 JE2 strain in rich media (TSB) were assessed by RT-qPCR. The bars represent the means of relative expression from at least three independent experiments. The error bars show standard errors of the means. Statistical differences were determined by Mann-Whitney $U$ Test except for the comparisons of the parental strain vs the fur mutant and the parental strain vs the zur mutant in which a unpaired Student's t-test was performed $\left.{ }^{*} P<0.05\right)$ 
affinity column, an SDS-PAGE gel indicated a homogenous single protein band (data not shown). Two promoters have been previously determined for the $c n t$ operon, one within the upstream region of $c n t K$ (cntK promoter) and the second one within the intergenic region between $c n t M$ and $c n t A$ genes (named $c n t A$ promoter) [8]. Incubation of Rsp with either the 494-bp cntK or the 381-bp cntA promoter fragments resulted in a DNA band shift (Fig. 4). These bands shifts were reduced in the presence of 200-fold excess unlabeled specific promoter region DNA and remained unchanged in the presence of a similar excess of salmon sperm DNA, indicating specific binding to the promoter DNA fragment.

\section{Discussion}

The Cnt system is essential for the optimal import of nickel, cobalt, zinc and ferrous iron when these metals are limited, and it contributes to virulence in $S$. aureus $[6,12,13]$.

Several studies have identified Fur and Zur as repressors of the Cnt system [6-8] but, no activators of the operon have been identified. In this study, we identified that the AraC-type global regulator Rsp is involved in the activation of the cnt operon by binding directly to the $c n t K$ and $c n t A$ promoters. Since both a Fur box and a Zur box are present upstream of $c n t K$ and $c n t A$ promoters [8], it is possible that Rsp binding involves one of those boxes. However, the expression of the Furregulated $s b n$ operon [14], was not changed in a $r s p$ mutant (data not shown), suggesting that Rsp does not bind to the Fur boxes in general. Another study demonstrated that Rsp upregulates agrA and downregulates ica by direct binding of their promoters [11]. The predicted binding motifs of the agrP2 and the ica promoters, however, are different [11] and at the same time no similar sequence was found in the $f n b A$ promoter, which reportedly also binds Rsp [15]. Those possible binding motifs were also not present in the cnt promoters. These findings favor our hypothesis that Rsp does not bind to the Fur box, and determination of the binding motif of Rsp will await further study. The upregulation of the Cnt system by Rsp was demonstrated to occur in both low and high metal conditions suggesting that Rsp acts to maintain a basal level expression of the cnt operon in the presence of Fur-mediated iron-dependent repression. Notably the effect was greatest when Fur repression was increased under high iron conditions. To evaluate the interaction of Rsp with Fur or Zur repressors, we constructed double mutants. Notably the increases in cnt gene expression levels in fur and zur single were not eliminated in the rsp double mutants. A partial counter effect of Rsp on Fur repression was seen for $c n t K$ and $c n t E$ and a partial counter effect of Rsp on Zur was seen for $c n t A$ and cntE. Thus, Rsp, Fur, and Zur can act independently of each other in affecting levels of cnt gene expression.

\section{Conclusions}

In conclusion, we identified for the first time an activator of the Cnt system, Rsp, that acts in both low and high iron conditions and contributes to a basal level of production of the StP synthesis genes and StP importers to scavenge free metals when needed. Rsp acts in addition to the known regulation by repressors Fur and Zur. This tight and complex regulation also could prevent the toxicity due to the StP accumulation by the activation of the expression of the StP exporter $c n t E$ gene [16].

\section{Methods}

Bacterial strains and growth conditions

All the strains and plasmids used in this study are summarized in Table 2. S. aureus strains were routinely cultivated in trypticase soy broth (TSB) and on tryptic soy agar plates (TSA), while E. coli strains were grown in Luria-Bertani broth (LB). Bacteria were grown at $37^{\circ} \mathrm{C}$ unless stated otherwise. The following antibiotics were obtained from Sigma-Aldrich (St. Louis, MO) and used for plasmid maintenance at the concentrations indicated: ampicillin, $100 \mu \mathrm{g} / \mathrm{ml}$; kanamycin, $25 \mu \mathrm{g} / \mathrm{ml}$ or $75 \mu \mathrm{g} / \mathrm{ml}$; and tetracycline, $10 \mu \mathrm{g} / \mathrm{ml}$.

\section{Construction of $S$. aureus mutant strains}

S. aureus USA300 fur and USA300 zur single mutants and USA300 fur rsp and USA300 zur rsp double mutants strains were created via bacterial phage $\phi 85$ transduction from S. aureus Newman fur::tet and S. aureus NCTC8325 zur::tet strains respectively as previously described [5]. Colonies of interest were selected on TSA plates containing sodium citrate $(10 \mu \mathrm{g} / \mathrm{ml})$ and tetracycline $(10 \mu \mathrm{g} / \mathrm{ml})$. Mutant candidates were isolated, and the mutants were confirmed by PCR and DNA sequencing.

\section{Construction of Rsp complementation plasmid}

To complement the $r s p$ mutant, the entire $r s p$ gene was amplified from USA300 chromosomal DNA using primers listed in supplementary table (Table S1) and cloned into shuttle vector pTZN10 [17]. The plasmid was extracted from $E$. coli $\mathrm{DH} 5 \alpha$, introduced into $S$. aureus RN4220, then into USA300 mutants, and maintained by the addition of chloramphenicol $(10 \mu \mathrm{g} / \mathrm{ml})$ to the culture medium. The plasmid insert was verified by DNA sequencing.

\section{RNA extraction and relative expression of the cnt operon genes by RT-qPCR}

Cultures were inoculated from $-80^{\circ} \mathrm{C}$ stocks into TSB broth supplemented with the appropriate antibiotic, grown at $37^{\circ} \mathrm{C}$ overnight, diluted 1:100 into fresh TSB 


\section{cntK)}

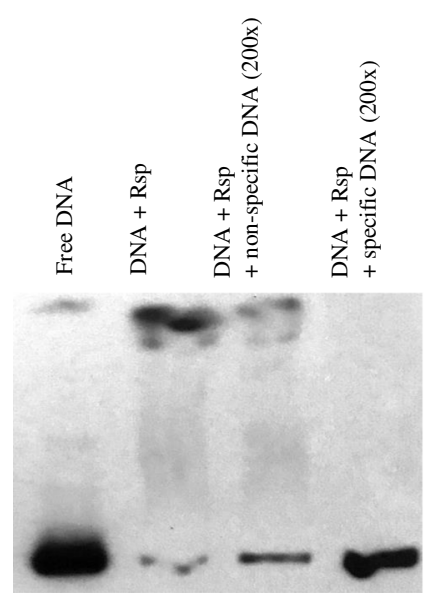

cntA)

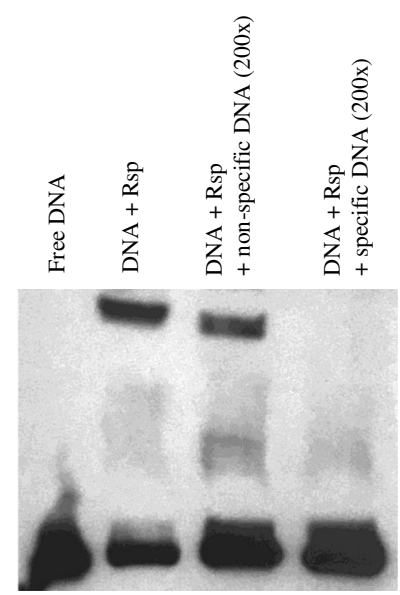

Fig. 4 Gel mobility shift assay with purified Rsp protein mixed with the biotinylated 494-bp sequence upstream of cntK (cntk) and (cntA) 381-bp sequence upstream of $c n t A$. Eight fmol of the biotin-labeled DNA was incubated with $1.5 \mu \mathrm{g}$ of purified protein. The reaction mixture was incubated for $20 \mathrm{~min}$ at room temperature and analyzed by 5\% nondenaturing polyacrylamide gel electrophoresis (PAGE). For the competition assay, a 200-fold excess of unlabeled specific DNA or nonspecific salmon sperm DNA was added to the reaction mixture prior to the incubation

broth with the same antibiotics, and grown for 2 to $3 \mathrm{~h}$ to an optical density at $600 \mathrm{~nm}\left(\mathrm{OD}_{600}\right)$ of $~ 0.5$. To measure cht operon expression under iron-depleted medium, $400 \mu \mathrm{M}$ dipyridyl (DIP) was added at an $\mathrm{OD}_{600}$ of 0.5 with or without the supplementation of $50 \mu \mathrm{M} \mathrm{FeSO}$. RNA Protect Bacteria Reagent (Qiagen) was added to the culture for immediate RNA stabilization prior to harvest the cells. Total S. aureus RNA was isolated using the Qiagen RNeasy mini kit (Qiagen, Valencia, CA) following the manufacturer's instructions and using lysostaphin for cell lysis. Reverse transcription followed by real-time quantitative PCR (RT-qPCR) was performed to determine the expression levels of the cnt operon genes. Comparison was made to the expression level of the housekeeping gene gmk [5]. cDNA was generated by reverse transcription using the Verso cDNA synthesis kit (Thermo Scientific) according to the manufacturer's protocol. SsoFast EvaGreen supermix and the QuantStudio 3 Real-time PCR system (Thermo Scientific) were employed for RT-qPCR using the synthesized cDNA as the template. Primers used are listed in the supplementary table (Table S1). At least three different assays with three independent cultures and RNA extractions were performed for each gene tested. Two-group comparisons of gene expression levels were evaluated by the Mann-Whitney test with the exception of the Students's t-test used for comparison of parental and fur and zur single mutants.

\section{Expression and purification of histidine-tagged Rsp protein}

E. coli SG13009 (pREP4) cells harboring rsp cloned into pQE-9 vector [11] were grown in LB supplemented with ampicillin $100 \mu \mathrm{g} / \mathrm{ml}$ plus kanamycin $25 \mu \mathrm{g} / \mathrm{ml}$ at $37^{\circ} \mathrm{C}$ $\left(\mathrm{OD}_{600}\right.$ of $\left.\sim 1\right)$ and then subjected to induction by 0.5 $\mathrm{mM}$ isopropyl- $\beta$-d-thiogalactopyranoside (IPTG) for $4 \mathrm{~h}$. After centrifugation at $10,000 \mathrm{rpm}$ for $30 \mathrm{~min}$ at $4{ }^{\circ} \mathrm{C}$ the cells were resuspended in lysis buffer $\left(50 \mathrm{mM} \mathrm{NaH} \mathrm{PO}_{4}\right.$, $\mathrm{pH} 8,300 \mathrm{mM} \mathrm{NaCl}$ ) at 0.04 volume of the original culture. We added benzonase nuclease (Sigma-Aldrich) and a complete mini protease inhibitor cocktail tablet (Roche) to the lysate for further sonication on ice for 10 cycles of $30 \mathrm{~s}$ with $30 \mathrm{~s}$ resting periods followed by centrifugation at $10,000 \mathrm{rpm}$ for $30 \mathrm{~min}$ at $4{ }^{\circ} \mathrm{C}$ and filtering the supernatant through a Steriflip-GP, $0.22-\mu \mathrm{m}$, polyethersulfone membrane (EMD Millipore, Billerica, MA). Nickel affinity chromatography (GE Healthcare, Marlborough, MA) using $5 \mathrm{ml}$ fractions and incremental concentrations of imidazole was performed for purification of the histidine-tagged Rsp protein. The fractions obtained were run on SDS-PAGE Coomassie gels and Western blotting (Invitrogen, Carlsbad, CA) was performed following the manufacturer's protocols. The appropriate fractions were then cleared of imidazole using PD-10 desalting columns (GE Healthcare, Marlborough, $\mathrm{MA}$ ) and concentrated on Amicon Ultra-15 (Ultracel 50 K) centrifugal filter units (EMD Millipore). The concentration was measured using a NanoDrop 1000 spectrophotometer (Thermo Scientific).

\section{Electrophoretic DNA mobility shift assays}

Using a LightShift chemiluminescent EMSA kit (Thermo Scientific, Wilmington, DE), the binding of Rsp to the labeled 494-bp region upstream of $c n t K$ and 381-bp region upstream of cntA was assessed. Both cntK and cntA 
Table 2 The strains and plasmids used in this study

\begin{tabular}{|c|c|c|}
\hline Strains or plasmids & Genotype or characteristic $(s)^{a}$ & References \\
\hline \multicolumn{3}{|l|}{ S. aureus strains } \\
\hline USA300 JE2 & Parental strain for the Nebraska Transposon Mutant Library & [10] \\
\hline NE1304 & rsp mutant from the Nebraska Transposon Mutant Library with erm gene insertion; Erm ${ }^{R}$ & [10] \\
\hline Newman fur::tet & fur mutant with tet gene insertion, Tet $^{R}$ & [12] \\
\hline NCTC8325 zur::tet & zur mutant with tet gene insertion, Tet $^{R}$ & [13] \\
\hline USA300 fur & fur mutant with tet gene insertion, $\operatorname{Tet}^{R}$ & This study \\
\hline USA300 zur & zur mutant with tet gene insertion, Tet $^{R}$ & This study \\
\hline USA300 fur rsp & fur rsp double mutant; $\operatorname{Tet}^{\mathrm{R}}, \mathrm{Erm}^{\mathrm{R}}$ & This study \\
\hline USA300 zur rsp & zur rsp double mutant; $\operatorname{Tet}^{R}, E{ }^{R}$ & This study \\
\hline
\end{tabular}

\section{E. coli strains}

SG13009 pREP4 (pQE-9-rsp) Derived from E. coli K12 harboring a plasmid to overexpressed rsp.

Plasmids

pZTN10

Escherichia coli/Staphylococcus aureus shuttle vector; $\mathrm{Amp}^{\mathrm{R}}, \mathrm{Cm}^{\mathrm{R}}$

pTZN10-rsp (pRsp)

pTZN10 derivative containing rsp gene from S. aureus; $\mathrm{Amp}^{\mathrm{R}}, \mathrm{Cm}^{\mathrm{R}}$

${ }^{a}$ Abbreviations: Erm ${ }^{R}$ Erythromycin resistance, Tet $^{R}$ Tetracycline resisatnce, $\mathrm{Amp}^{R}$ Ampicillin resisatnce, $\mathrm{Cm}^{R}$ Chloramphenicol resistance

fragments were amplified using a biotinylated $5^{\prime}$ primer (Integrated DNA Technologies, Coralville, IA) (Table S1) and diluted to $\sim 8$ fmol per reaction. LightShift chemiluminescent EMSA kit controls were run alongside mixtures of biotinylated DNA and various protein concentrations $(65$ to $365 \mu \mathrm{g} / \mathrm{ml})$ on an acrylamide nondenaturing gel, transferred to a $0.45-\mu \mathrm{m}$ nylon membrane (Thermo Scientific, Wilmington, DE), and detected on autoradiography film (GE Healthcare, Marlborough, MA). Specificity of binding was determined by addition of 200fold excess of specific unlabeled DNA in comparison to the same excess of nonspecific salmon sperm DNA.

\section{Supplementary information}

Supplementary information accompanies this paper at https://doi.org/10. 1186/s12866-020-02013-0.

Additional file 1 : Table S1 Primers used in this study.

\begin{abstract}
Abbreviations
Stp: Staphylopine; TSB: Trypticase soy broth; TSA: Tryptic soy agar plates; LB: Luria-Bertani broth; RT-qPCR: Real-time quantitative PCR; DIP: Dipyridyl; IPTG: Isopropyl- $\beta$-d-thiogalactopyranoside; SEM: Error standard of the mean; Erm ${ }^{R}$ : Erythromycin resistance; Tet ${ }^{R}$ : Tetracycline resisatnce; Amp ${ }^{R}$ : Ampicillin resisatnce; $\mathrm{Cm}^{\mathrm{R}}$ : Chloramphenicol resistance
\end{abstract}

\section{Acknowledgments}

We thank Min Li (Department of Laboratory Medicine, Renji Hospital, School of Medicine, Shanghai Jiao Tong University, Shanghai, China) for providing the strain E. coli SG13009 pREP4 (pQE-9-rsp); Simon J. Foster (Department of Molecular Biology and Biotechnology, University of Sheffield, Sheffield, UK) for providing the strain S. aureus NCTC8325 zur:tet and Eric P. Skaar (Department of Pathology, Microbiology and Immunology, Vanderbilt University Medical Center, Nashville, TN, USA) for providing the strain S. aureus Newman fur:tet. We also thank Suzanne Walker (Department of Microbiology and Immunology, Harvard Medical School, Boston, MA, USA) for providing the phage-based ultrahigh-density transposon library and protocols.

\section{Authors' contributions}

LV and DCH participated in the design of the study. LV performed all the experiments and was the mayor contributor in writing the manuscript. DCH revised the manuscript carefully. All authors read and approved the final manuscript.

\section{Funding}

The work was supported by the National Institutes of Health, United States Public Health Service grants R37-Al23988 and P01-Al083214 (to David C. Hooper). The funders had no role in the design of the study, collection, analysis or interpretation of data, or in writing the manuscript.

\section{Availability of data and materials}

All data generated or analyzed during this study are included in this published article [and its supplementary information files]. USA300 fur and USA300 zur mutants have been included in the GenBank with accession numbers MW048529 and MW048528 respectively.

\section{Ethics approval and consent to participate}

Not applicable.

\section{Consent for publication}

Not applicable.

\section{Competing interests}

All authors declare no competing interests.

Received: 2 June 2020 Accepted: 15 October 2020

Published online: 28 October 2020

\section{References}

1. Hammer ND, Skaar EP. The impact of metal sequestration on Staphylococcus aureus metabolism. Curr Opin Microbiol. 2012;15:10-4.

2. Corbin BD, Seeley EH, Raab A, Feldmann J, Miller MR, Torres VJ, Anderson KL, Dattilo BM, Dunman PM, Gerads R, Caprioli RM, Nacken W, Chazin WJ, Skaar EP. Metal chelation and inhibition of bacterial growth in tissue abscesses. Science. 2008;319:962-5.

3. Cassat JE, Skaar EP. Metal ion acquisition in Staphylococcus aureus: overcoming nutritional immunity. Semin Immunopathol. 2012;34:215-35.

4. Ghssein G, Brutesco C, Ouerdane L, Fojcik C, Izaute A, Wang S, Hajjar C, Lobinski R, Lemaire D, Richaud P, Voulhoux R, Espaillat A, Cava F, Pignol D, Borezée-Durant E, Arnoux P. Biosynthesis of a broad-spectrum nicotianaminelike metallophore in Staphylococcus aureus. Science. 2016;352:1105-9.

5. Ding Y, Fu Y, Lee JC, Hooper DC. Staphylococcus aureus NorD, a putative efflux pump coregulated with the Opp1 oligopeptide permease, contributes selectively to fitness in vivo. J Bacteriol. 2012;194:6586-93. 
6. Remy L, Carrière M, Derré-Bobillot A, Martini C, Sanguinetti M, BorezéeDurant E. The Staphylococcus aureus Opp1 ABC transporter imports nickel and cobalt in zinc-depleted conditions and contributes to virulence. Mol Microbiol. 2013;87:730-43.

7. Grim KP, San Francisco B, Radin JN, Brazel EB, Kelliher JL, Párraga Solórzano PK, Kim PC, McDevitt CA, Kehl-Fie TE. The metallophore staphylopine enables Staphylococcus aureus to compete with the host for zinc and overcome nutritional immunity. MBio. 2017;8:e01281-17.

8. Fojcik C, Arnoux P, Ouerdane L, Aigle M, Alfonsi L, Borezée-Durant E. Independent and cooperative regulation of staphylopine biosynthesis and trafficking by Fur and Zur. Mol Microbiol. 2018;108:159-77.

9. Santiago M, Matano LM, Moussa SH, Gilmore MS, Walker S, Meredith TC. A new platform for ultra-high-density Staphylococcus aureus transposon libraries. BMC Genomics. 2015;16:2521361-3.

10. Fey PD, Endres JL, Yajjala VK, Widhelm TJ, Boissy RJ, Bose JL, Bayles KW. A genetic resource for rapid and comprehensive phenotype screening of nonessential Staphylococcus aureus genes. MBio. 2013;4:e00537-12.

11. Li T, He L, Song Y, Villaruz AE, Joo HS, Liu Q, Zhu Y, Wang Y, Qin J, Otto M, Li M. AraC-type regulator Rsp adapts Staphylococcus aureus gene expression to acute infection. Infect Immun. 2015;84:723-34.

12. Torres VJ, Attia AS, Mason WJ, Hood MI, Corbin BD, Beasley FC, Anderson KL, Stauff DL, McDonald WH, Zimmerman LJ, Friedman DB, Heinrichs DE, Dunman PM, Skaar EP. Staphylococcus aureus fur regulates the expression of virulence factors that contribute to the pathogenesis of pneumonia. Infect Immun. 2010;78:1618-28.

13. Lindsay JA, Foster SJ. zur: a Zn (2+)-responsive regulatory element of Staphylococcus aureus. Microbiology. 2001;147:1259-66.

14. Dale SE, Doherty-Kirby A, Lajoie G, Heinrichs DE. Role of siderophore biosynthesis in virulence of Staphylococcus aureus: identification and characterization of genes involved in production of a siderophore. Infect Immun. 2004;72:29-37.

15. Lei MG, Cue D, Roux CM, Dunman PM, Lee CY. Rsp inhibits attachment and biofilm formation by repressing fnbA in Staphylococcus aureus MW2. J Bacteriol. 2011;193:5231-41.

16. Chen C, Hooper DC. Intracellular accumulation of staphylopine impairs the fitness of Staphylococcus aureus cntE mutant. FEBS Lett. 2019;593:1213-22.

17. Nakaminami H, Noguchi N, Nishijima S, Kurokawa I, Sasatsu M.

Characterization of the pTZ2162 encoding multidrug efflux gene aacB from Staphylococcus aureus. Plasmid. 2008;60:108-17.

\section{Publisher's Note}

Springer Nature remains neutral with regard to jurisdictional claims in published maps and institutional affiliations.

Ready to submit your research? Choose BMC and benefit from:

- fast, convenient online submission

- thorough peer review by experienced researchers in your field

- rapid publication on acceptance

- support for research data, including large and complex data types

- gold Open Access which fosters wider collaboration and increased citations

- maximum visibility for your research: over $100 \mathrm{M}$ website views per year

At BMC, research is always in progress.

Learn more biomedcentral.com/submissions 